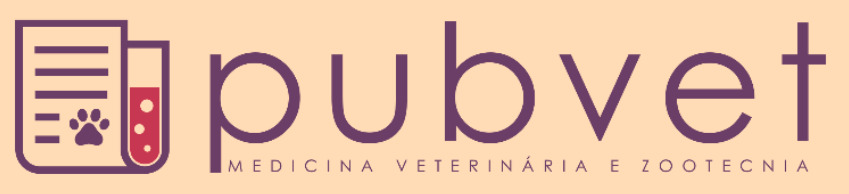

https://doi.org/10.31533/pubvet.v14n6a591.1-12

\title{
A relação entre microbiota intestinal e células do sistema imune no desenvolvimento da Doença Inflamatória Intestinal em gatos: revisão
}

\author{
Reginaldo Pereira de Sousa-Filho ${ }^{1 *} \bullet$, Keytyanne de Oliveira Sampaio ${ }^{2} \bullet$, Mariana Araújo \\ Rocha $^{30}$, Barbara Kelly Lima de Castro ${ }^{\circ}{ }^{\circ}$, Alexandre Tavares Camelo Oliveira ${ }^{\circ}{ }^{\circ}$, Belarmino \\ Eugênio Lopes Neto ${ }^{5}$, Robério Gomes Olinda $^{6}{ }^{\circ}$, Diana Célia Sousa Nunes- Pinheiro ${ }^{7}$ \\ ${ }^{I}$ Doutorando no Programa de pós-graduação em Ciências Veterinárias, Universidade Estadual do Ceará. Fortaleza -CE Brasil. \\ ${ }^{2}$ Mestranda no Programa de pós-graduação em Medicina Veterinária, Universidade Federal Rural de Pernambuco. Recife- PE Brasil \\ ${ }^{3}$ Residente em Clínica Médica Veterinária na Universidade Federal do Semi-Árido- UFERSA. \\ ${ }^{4}$ Graduando em Medicina Veterinária da Universidade Estadual do Ceará (UECE), Faculdade de Veterinária (FAVET). \\ ${ }^{5}$ Docente da Faculdade de Medicina Veterinária da Universidade Estadual do Ceará- UECE. \\ ${ }^{6}$ Docente da Faculdade de Medicina Veterinária da Universidade de Fortaleza- Unifor. \\ ${ }^{7}$ Pesquisadora do Programa de pós-graduação em Ciências Veterinárias. Universidade Estadual do Ceará (Fortaleza, CE e Brasil). \\ *Autor para correspondência, E-mail: reginaldo.filho@uece.br
}

Resumo. Recentes estudos sugerem interações dinâmicas entre a microbiota residente e o sistema imunológico do hospedeiro contribuindo para as respostas imunes local e sistêmica, bem como sua regulação, e que repercutem para a manutenção da saúde e da doença. A Doença Inflamatória Intestinal (DII) se caracteriza como um desequilíbrio imunológico na relação entre o epitélio intestinal, a microbiota e células da imunidade inata e adaptativa, podendo se apresentar com diversas sintomatologias clínicas. Em humanos, a DII pode ser classificada em Doença de Crohn (DC) e Colite Ulcerativa (CoU). Em gatos, a DII pode se manifestar similarmente como em humanos, dependendo do segmento intestinal acometido, com sintomatologia também semelhante. A causa da DII permanece desconhecida; entretanto, evidências sugerem que uma resposta imune anormal contra os microrganismos residentes no intestino seja responsável pela doença em indivíduos geneticamente suscetíveis. Esta revisão tem como foco a importância da DII no paciente felino e a dificuldade no diagnóstico diferencial das enteropatias crônicas felinas. Com objetivo de um maior entendimento da imunopatogenia da doença, foram compilados artigos científicos relevantes publicados nas últimas décadas referentes a DII com ênfase na doença felina, o papel da microbiota e do sistema imunológico, a fim de auxiliar o entendimento do clínico e do patologista veterinário.

Palavras chave: enteropatia, felino, microbiota, sistema imunológico

\section{The relationship between intestinal microbiota and immune cells in the development of Inflammatory Bowel Disease in cats: A review}

\begin{abstract}
Recent studies suggest dynamic interactions between the resident microbiota and the host's immune system, contributing to the local and systemic immune responses, as well as their regulation, and that impact on the maintenance of health and disease. Inflammatory Bowel Disease (IBD) is characterized as an immune imbalance in the relationship between the intestinal epithelium, the microbiota and innate and adaptive immunity cells, and may present with several clinical symptoms. In humans, IBD can be classified into Crohn's disease (CD) and ulcerative colitis (CoU). In cats, IBD can manifest similarly as in humans, depending on the intestinal segment affected, with similar symptoms. The cause of IBD remains unknown; however, evidence suggests that an abnormal immune response against microorganism's resident in the intestine is responsible for the disease in genetically
\end{abstract}


susceptible individuals. This review focuses on the importance of IBD in the feline patient and the difficulty in the differential diagnosis of feline chronic enteropathies. In order to gain a better understanding of the immunopathogenesis of the disease, relevant scientific articles published in the last decades concerning IBD with an emphasis on feline disease, the role of the microbiota and the immune system, were compiled in order to help the understanding of the veterinary clinician and pathologist.

Keywords: enteropathy, feline, immune system, microbiota

\section{Introdução}

$\mathrm{O}$ trato gastrointestinal é exposto cronicamente a vários antígenos encontrados em bactérias e alimentos. O epitélio intestinal é constituído por um grupo de células especializadas de camada única e que sob a interação do sistema imune garante a homeostase local. No estado normal, na ausência de inflamação, a homeostase intestinal é mantida pela supressão das respostas imunes excessivas aos antígenos considerados estranhos (Lee et al., 2018).

A mucosa intestinal é caracterizada por apresentar vilosidades intestinais, que são projeções alongadas da mucosa em direção ao lúmen, sendo revestida por um epitélio cilíndrico simples, onde se observam células colunares altas, de função absortiva, onde no ápice há a formação de bordas em escova, formadas pelo conjunto de microvilosidades e glicocálix. Entre as células absortivas, encontram-se também, células caliciformes, que apresentam grânulos contendo mucina no seu citoplasma apical, sendo responsáveis pela produção do muco intestinal (Birchenough et al., 2015). As células de Paneth são células especializadas presentes na base das criptas do intestino delgado e possuem funções secretoras de substâncias bactericidas, principalmente na produção de defensinas (Geremia et al., 2014). As células $\mathrm{M}$ são caracterizadas por suas microfibras ou pequenos microvilos na superfície celular, não secretam muco ou enzimas digestivas, sendo a sua principal função, a endocitose seletiva de antígenos e sua apresentação para macrófagos intra-epiteliais e linfócitos, que migram para os linfonodos, iniciando a resposta imune local (Mabbott et al., 2013).

A integridade da barreira epitelial é mantida por junções estreitas, aderentes e desmossomos. Na Doença Intestinal Inflamatória (DII) essa barreira epitelial apresenta-se defeituosa e o aumento da permeabilidade intestinal são observados em pacientes, entretanto não é determinado se essas alterações representavam a causa ou consequência da inflamação crônica (Geremia et al., 2014). A DII envolve a desregulação das complexas interações entre os fatores ambientais, microbioma, epitélio intestinal e sistema imune local. Fatores como: desequilíbrios microbianos intestinais, componentes da dieta, antibioticoterapias, vacinações, tratamentos antiparasitários excessivos, fatores imunológicos e fatores genéticos, são importantes na causa e perpetuação da inflamação crônica em indivíduos susceptíveis (Jergens, 2012). Considerando-se a importância da DII no paciente felino e a dificuldade no diagnóstico diferencial das enteropatias crônicas felinas, o objetivo desse trabalho foi reunir a literatura atual sobre o tema, com ênfase no papel da microbiota felina, do sistema imune intestinal e a interação destes no desenvolvimento e manutenção da doença, para um maior entendimento da enfermidade na espécie, colaborando para uma melhor visão e entendimento clínico-patológico.

\section{Doença inflamatória intestinal felina: etiopatogenia e sinais clínicos}

A Doença Inflamatória Intestinal Felina (DIIF) representa um grupo de doenças gastrintestinais crônicas e idiopáticas caracterizada por apresentar sinais clínicos recorrentes do trato gastrintestinal, como vômitos, diarreia e perda de peso, associados as evidências histológicas de inflamação pela presença de infiltrados difusos de células inflamatórias, podendo ocorrer no intestino delgado ou grosso (Fragata \& Santos, 2008). A etiologia dessa inflamação não é totalmente esclarecida, porém são conhecidos fatores associados, como genéticos, bactérias, parasitas, dieta e desregulação da resposta imune ao microbioma intestinal (Jergens, 2012). A perda de tolerância oral a antígenos microbianos ou dietéticos luminais e alterações na função de barreira epitelial intestinal parecem estar envolvidos na patogênese da doença. A inflamação é estabelecida com o dano tecidual e os mecanismos de hipersensibilidade parecem perpetuar o processo inflamatório em função da alta quantidade de antígenos no ambiente intestinal que invadem a lâmina própria (Kleinschmidt et al., 2010a). 
A DII é uma das patologias mais comuns na clínica de cães e gatos com sinais gastrointestinais crônicos (Waly et al., 2014). A DIIF pode ser classificada de acordo com a natureza do infiltrado inflamatório, sendo o padrão mais comum o linfo-plasmocítico (Figura 1). No entanto, poderá ocorrer uma migração celular granulomatosa predominantemente ou de eosinófilos (padrão eosinofílico) ou de neutrófilos (padrão neutrofílico), suspeitando-se, nestes casos, de uma maior participação de parasitas intestinais ou de infecções bacterianas, respectivamente (Janeczko et al., 2008; Jergens, 2012).

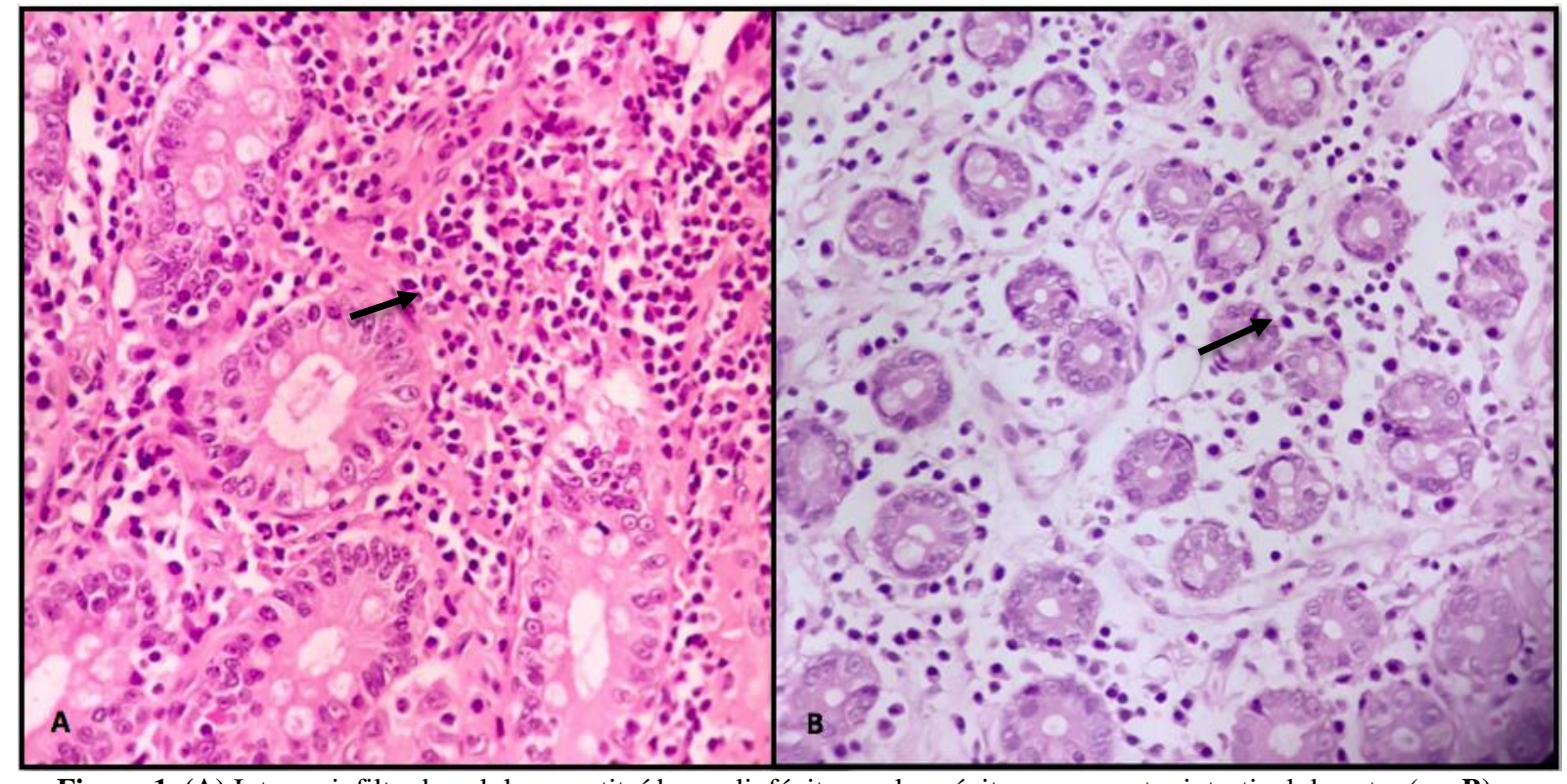

Figura 1. (A) Intenso infiltrado celular constituído por linfócitos e plasmócitos em amostra intestinal de gato. ( Infiltrado mononuclear discreto em amostra intestinal de gato (H\&E, 100x).

A DII é uma patologia de diagnóstico por exclusão, devendo-se inicialmente descartar quadros de hipertireoidismo, parasitismo intestinal, intolerância alimentar e linfoma, visto que um infiltrado linfocítico-plasmocítico pode ser encontrado nestes diagnósticos diferenciais e até em pacientes sem sinais clínicos gastrointestinais (Marsilio \& Steiner, 2015; Waly et al., 2004).

O diagnóstico deve ser baseado nos sinais clínicos, exames laboratoriais e histopatológicos, cujas amostras intestinais deverão ser obtidas preferencialmente pela celiotomia e biópsia incisional transmural, favorecendo a análise de todas as camadas intestinais (Day et al., 2008). Coletas por técnicas endoscópicas são limitadas já que não permitem a análise de todas as camadas intestinais, além de impossibilitar a biópsia de segmentos importantes, como o íleo e segmentos extra-intestinais, como linfonodos mesentéricos. A inclusão de biópsias extra-intestinais na análise histopatológica pode favorecer ao diagnóstico precoce da DIIF ou de neoplasias intestinais, como linfomas e mastocitomas, cujos quadros podem ainda não estar acometendo os segmentos intestinais biopsiados (Kleinschmidt et al., 2010b).

As análises hematológicas e bioquímicas são importantes para auxiliar o monitoramento do paciente em tratamento e determinar o prognóstico, já que estas permitem avaliar repercussão sistêmica do processo inflamatório ou o acometimento de outros órgãos, como pâncreas e fígado, sendo relativamente comum o envolvimento concomitantemente destes (Hill \& Van Winkle, 1993). O estadiamento da DII pode ser realizado pelo Índice de Atividade de Enteropatia Crônica Felina (IAECF) (Tabela 1), que é baseado na pontuação em escores, de acordo com a presença e intensidade dos sinais clínicos (vômito, atividade, perda de peso, apetite, diarreia) e alterações em exames bioquímicos (proteínas totais, alaninamino transferase, fosfatase alcalina e fósforo séricos) e endoscópico/histopatológico (Jergens et al., 2010). A recomendação do estadiamento é fortemente sugerida principalmente para o acompanhamento da resposta terapêutica empregada (Jergens, 2012).

Os achados histológicos onde se incluem o tipo de infiltrado observado e a severidade das alterações tais como, fibrose, atrofia de vilosidades intestinais (Figura 2) e erosão de mucosa, estão fortemente relacionados com as citocinas pró-inflamatórias liberadas no sítio e que estão associadas ao dano 
tecidual e, consequentemente, com a repercussão dos sinais clínicos. Estes por sua vez reforçam à importância do estadiamento pelo IAECF (Jergens, 2012).

Tabela 1. Cálculo do Índice de Atividade de Enteropatia Crônica em Felinos (IAECF). A magnitude da soma total é proporcional ao grau de atividade inflamatória. Adaptado de Jergens (2012).

\begin{tabular}{|c|c|c|c|c|c|}
\hline \multirow{2}{*}{$\frac{\text { Parâmetros }}{\text { Diminuição de atividade }}$} & \multicolumn{4}{|c|}{ Intensidade, escores } & \multirow{2}{*}{$\frac{\text { Subtotal }}{0-3}$} \\
\hline & Normal (0) & Leve (1) & Moderada (2) & Severa (3) & \\
\hline Diminuição do apetite & Normal (0) & Leve (1) & Moderada (2) & Severa (3) & $0-3$ \\
\hline Vômito & Ausente (0) & 1x/semana (1) & 2 a $3 x /$ semana $(2)$ & $>3 \mathrm{x} / \mathrm{semana}(3)$ & $0-3$ \\
\hline Diarreia & Ausente (0) & 2 a $3 x /$ dia (1) & 4 a $5 x / d i a(2)$ & $>5 \mathrm{x} / \mathrm{dia}(3)$ & $0-3$ \\
\hline Perda de peso & Ausente (0) & Regular (1) & Moderada (2) & Severa (3) & $0-3$ \\
\hline Lesões endoscópicas & \multicolumn{2}{|c|}{ Não (0) } & \multicolumn{2}{|c|}{$\operatorname{Sim}(1)$} & $0-1$ \\
\hline Proteínas totais séricas & \multicolumn{2}{|c|}{ Normal (0) } & \multicolumn{2}{|c|}{ Aumentada (1) } & $0-1$ \\
\hline Alanina aminotransferase sérica & \multicolumn{2}{|c|}{ Normal (0) } & \multicolumn{2}{|c|}{ Aumentada (1) } & $0-1$ \\
\hline Fosfatase alcalina sérica & \multicolumn{2}{|c|}{ Normal $(0)$} & \multicolumn{2}{|c|}{ Aumentada (1) } & $0-1$ \\
\hline Fósforo Total sérico & \multicolumn{2}{|c|}{ Normal (0) } & \multicolumn{2}{|c|}{ Aumentado (1) } & $0-1$ \\
\hline
\end{tabular}

A DIIF possui similaridades com as doenças intestinais inflamatórias humanas, como a Doença de Crohn (DC) e a Colite Ulcerativa (CoU). Fatores imunopatogênicos, manifestações clínicas (Tabela 2), alterações da microbiota intestinal e a resposta imune exacerbada são semelhantes (Dandrieux, 2016).

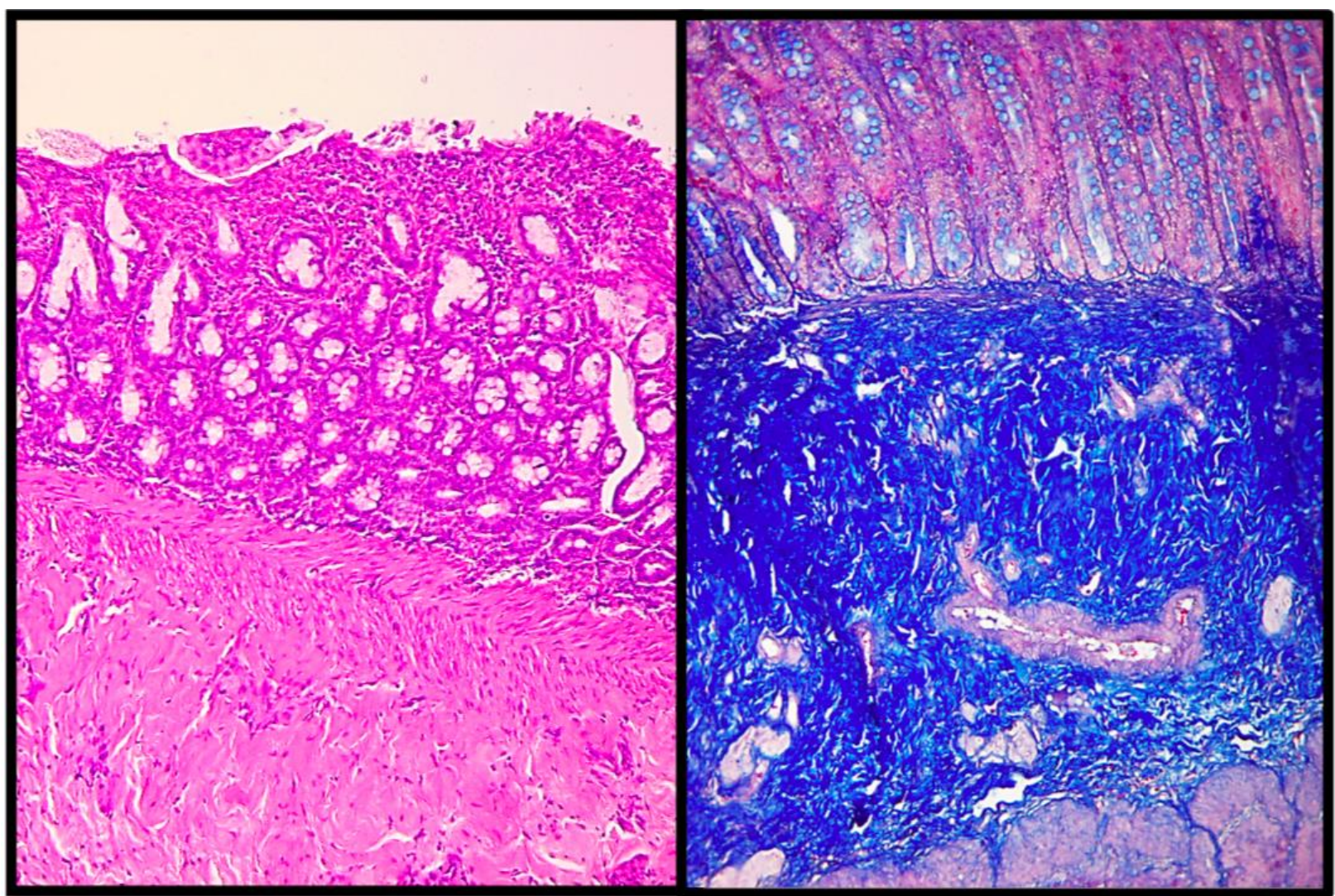

Figura 2. (A) Atrofia de vilosidades e infiltrado inflamatório na lâmina própria em amostra intestinal de gato com DII (H/E. 100X). (B) Intensa fibrose em camada submucosa de amostra intestinal de gato com DII (Tricômio de Masson. 100X).

\section{Importância da microbiota na doença inflamatória intestinal}

Um ecossistema microbiano equilibrado é de importância crucial não só para os intestinos, pois fornece estímulos para o sistema imunológico, ajuda na defesa contra enteropatógenos e fornece benefícios nutricionais, modulando a saúde e a doença do hospedeiro. 
Tabela 2. Manifestações clínicas da Doença Intestinal Inflamatória Humana (Doença de Crohn - DC; Colite Ulcerativa - CoU; Doença Celíaca - DCe) e Doença Intestinal Inflamatória Felina (DIIF).

\begin{tabular}{|c|c|c|c|c|}
\hline Manifestações clínicas ${ }^{1}$ & $\mathrm{DC}$ & $\mathrm{CoU}$ & $\mathrm{DCe}$ & DIIF \\
\hline Anorexia & $+^{(2)}$ & + & - & ++ \\
\hline Vômito & + & + & + & +++ \\
\hline Regurgitação & - & - & + & + \\
\hline Polifagia & - & - & - & + \\
\hline Diarreia & +++ & +++ & +++ & + \\
\hline Tenesmo & + & + & - & + \\
\hline Hematoquezia & - & ++ & - & + \\
\hline Dor abdominal & + & + & ++ & + \\
\hline Perda de peso & ++ & ++ & - & + \\
\hline Hipovitaminose B12 & - & - & + & + \\
\hline Colangite & + & + & - & ++ \\
\hline Hipoalbuminemia & - & - & + & + \\
\hline Abscessos/ fístulas intestinais & ++ & ++ & + & - \\
\hline Dermatites & - & - & + & + \\
\hline Endocrinopatias & - & - & + & - \\
\hline
\end{tabular}

(1) Alterações clínicas mais prevalentes segundo Jergens (2012), Pascual et al. (2014) e Aaron et al. (2019). ${ }^{2}$ Escores de acordo com a prevalência: ausente (-); leve (+); moderado (++); intenso (+++).

Em experimentos com camundongos livre de germes, verificou- se que a presença de bactérias é importante para o desenvolvimento adequado da estrutura intestinal, já que nestes, verificou- se uma diminuição do tamanho das vilosidades (Suchodolski, 2016). Pois, um desequilíbrio criado por uma mudança em uma espécie ou família microbiana específica ou em toda a comunidade comensal, pode afetar toda a resposta imunológica local e também afetar outros sistemas orgânicos. Os metabólitos bacterianos provindos do lúmen intestinal e entregues à barreira epitelial, conhecidos como "mobilomas", são os principais mensageiros do lúmen intestinal capazes de induzir respostas inflamatórias extraintestinais, verificadas nos quadros de comorbidades (Tabela 2) associadas a DII (Aaron et al., 2019).

As interações entre bactérias intestinais e o sistema imunológico do hospedeiro são mediadas pelo contato direto entre bactérias e metabólitos microbianos com as células do sistema imune inato através dos receptores de reconhecimento de padrão molecular (PRR), como os receptores do tipo Toll (Tolllike receptors, TLR) e os receptores do tipo NOD (Nucleotide-binding oligomerization domain) (Suchodolski, 2016). O gene do receptor NOD2 foi o primeiro a ser identificado para conferir maior risco à DC, com três mutações já identificadas, principalmente em população de origem européia. Essas mutações podem resultar em resposta inadequada, gerando produção reduzida de substâncias bactericidas, invasão microbiana patogênica e ativação de vias inflamatórias com excesso de respostas mediadas por Linfócitos $\mathrm{T}$ auxiliares efetores do tipo 1 (Th1) (Geremia et al., 2014). Mutações semelhantes em NOD2 foram verificadas em cães de raça Pastor Alemão com quadro de DII (Kathrani et al., 2010); entretanto ainda não investigado em gatos.

O papel da microbiota intestinal na patogênese da DIIF vem sendo estudado, entretanto ainda existe uma grande dificuldade em se determinar se o desequilíbrio da mesma seria a causa ou consequência da DIIF (Mosca et al., 2016). Dados comprovados, como a resposta de algumas enteropatias ao tratamento clínico baseado em antibioticoterapia (Jergens, 2012), a observação de maior predisposição da inflamação, em regiões anatômicas de íleo terminal e cólon, onde ocorre uma relativa estase fecal, em humanos (Kleinschmidt et al., 2010a) e a relação negativa entre a cirurgia de apendicectomia e a CoU (Danese et al., 2004) são condizentes com a ideia de que as bactérias intestinais contribuem para a resposta inflamatória.

A resposta imunológica exacerbada contra antígenos microbianos é reconhecida há muito tempo na DII humana. Pacientes com DC apresentam anticorpos específicos circulantes contra antígenos microbianos, incluindo Saccharomyces cerevisiae, proteína C da membrana externa de Escherichia coli, e antiPseudomonas fluorescens. O mesmo ocorre para anticorpos contra glicanos, componentes superficiais 
comuns de microrganismos e outras células humanas e animais (Souza \& Fiocchi, 2016). O agravamento da DC após a exposição da mucosa a conteúdos luminais no pós-operatório nestes pacientes, sugerem também um papel importante da microbiota na patogênese da doença (Souza \& Fiocchi, 2016).

A possibilidade de as bactérias estimularem a resposta inflamatória da mucosa é suportada pela capacidade das bactérias entéricas, incluindo E. coli, Salmonella spp e Clostridium spp, induzirem à secreção de citocinas pró-inflamatórias (Dandrieux, 2016)(Abraham \& Cho, 2009). A imunidade na mucosa intestinal pode ser regulada pela microbiota constituída de bactérias filamentosas segmentares, Clostridia e Bacteroides fragilis, os quais favorecem a ativação e diferenciação de subpopulações distintas de células $\mathrm{T}$ efetoras, como as células $\mathrm{T}$ auxiliares do tipo 17 (Th17), células $\mathrm{T}$ regulatórias (Treg) e células T auxiliares do tipo 1 (Th1), respectivamente (Souza \& Fiocchi, 2016).

Com relação as células Th17 no intestino, tem sido relatado que a microbiota endógena parece estar envolvida na diferenciação destas células (Dandrieux, 2016),e que sua presença em diferentes partes do intestino é dependente do grau de colonização por bactérias comensais. Em camundongos, as células Th17 são encontradas em números elevados na lâmina própria do íleo e do cólon, mas não no duodeno, jejuno, linfonodos mesentéricos ou baço, locais aonde a microbiota é mais escassa. Apoiando isso, diferentes estudos mostraram que a presença de células Th17 no intestino é visivelmente reduzida em camundongos tratados com antibióticos ou livres de germes (Gálvez, 2014). Portanto, a disbiose provoca desequilíbrio nas subpopulações celulares do componente de defesa tecidual. A disbiose presente na DII humana é vista de forma quantitativa e qualitativa, já que ocorre uma abundância em Bacteroidetes e Proteobacteria e redução das bactérias do filo Firmicutes (Faecailbacterium prausnitz) (Dandrieux, 2016). Também é documentada mudanças na microbiota intestinal de pessoas com CoU (Ni et al., 2017).

Os principais grupos bacterianos intestinais de gatos são semelhantes aos encontrados em outros mamíferos, como Firmicutes, Bacteroidetes, Actinobacteria e Proteobacteria, os quais constituem mais de 99\% da microbiota intestina (Johnston et al., 2001). Em cultura bacteriana do suco duodenal de gatos foi demonstrado que havia menos bactérias microaerofílicas lumenais em pacientes com sinais clínicos de doença gastrointestinal quando comparados aos gatos saudáveis. Foi também observado que o número total de bactérias da mucosa em gatos estava fortemente associado às mudanças na arquitetura da mesma, e na densidade de infiltrados celulares, particularmente macrófagos (Johnston et al., 2001).

Alterações como atrofia e fusão da mucosa intestinal são associadas com o aumento dos sinais clínicos intestinais e com o aumento do número de bactérias como Enterobacteriaceae, E. coli e Clostridium spp que representam $91 \%$ da microbiota de gatos com doença gastrointestinal. Em pacientes com a mucosa intestinal saudável, estas bactérias representam apenas $6 \%$ da flora comensal em comparação a $91 \%$ da microbiota da mucosa em gatos com sinais de doença gastrointestinal. Além disso, há uma super regulação de citocinas pro-inflamatórias (particularmente IL-1, IL-8 e IL-12) nestes pacientes (Janeczko et al., 2008), o que evidencia o quadro de desequilíbrio do microbioma nos animais afetados pela DII. Portanto, essas informações demonstram que a localização das bactérias pode sugerir uma maior participação destas na indução da resposta inflamatória da mucosa: Neste sentido, Janeczko et al. (2008) verificaram que as Enterobacteriaceae são as bactérias dominantes da mucosa de gatos com sinais de doença gastrointestinal, representando mais de $66 \%$ da flora intestinal, nestes pacientes, e que a $E$. coli, em gatos com DII, foram mais abundantes no muco sobre o epitélio superficial. Também tem sido relatada a presença de aproximadamente $10 \%$ de bactérias Clostridium spp. no epitélio superficial e nos tecidos mais profundos de gatos afetados, enquanto que em gatos saudáveis sua localização se restringe ao muco livre. Isto pode representar uma invasão oportunista por Clostridium spp. ou talvez a presença de uma cepa patogênica relacionada à DII. Esses dados estabelecem ainda que a densidade e a composição da microbiota da mucosa estão relacionadas à presença e gravidade da inflamação intestinal em gatos e sugerem que as bactérias da mucosa estejam envolvidas na etiopatogenia da DII felina (Janeczko et al., 2008).

A microbiota do intestino delgado, especialmente Lactobacillus spp e Clostridium spp, causa desconjugação de ácidos biliares e quando desregulada podem prejudicar a absorção de gordura, além de ocasionar, a destruição das enzimas de borda em escova, danos nas proteínas transportadoras e consequente diminuição da absorção de nutrientes (por exemplo, vitamina B12) (Suchodolski, 2016). 
Ainda, como consequência da disbiose, as enterotoxinas produzidas por bactérias patogênicas podem estimular as secreções de líquidos nas mucosas, destruição das vilosidades e a perda de área da superfície, reduzindo a capacidade de absorção da mucosa, resultando em diarreia. Essa disfunção da barreira mucosa pode levar a um aumento da permeabilidade intestinal e translocação bacteriana clinicamente significativa (Suchodolski, 2016).

Similarmente a humanos e cães, a quantidade de fibras solúveis (prebióticos) e macronutrientes (teor de proteínas) presentes na dieta podem modular a microbiota felina. Acredita-se também que, mudanças na microbiota intestinal levam a alterações metabólicas, gerando mudanças funcionais como a produção de ácidos graxos de cadeia curta (AGCCs) através da fermentação de carboidratos indigeríveis, produzidos principalmente por Clostridia spp., que parece aumentar a função das células Treg na mucosa intestinal (Duboc et al., 2013; Grigg \& Sonnenberg, 2017). Em ratos, os AGCCs derivados da microbiota intestinal induzem a produção de IL-10 por células Th1 específica de antígeno microbiano, mediada por receptores acoplados à proteína $\mathrm{G}$, diminuindo a severidade de colites.

Outra evidência importante é que no trato gastrointestinal saudável existe um gradiente de oxigênio devido à difusão deste, da mucosa do hospedeiro para o lúmen do intestino. Assim, as bactérias aderentes à mucosa intestinal têm maior tolerância ao oxigênio e à expressão da catalase, em relação as outras do lúmen intestinal. Como a inflamação é um estado oxidativo, pode-se esperar que ela promova o crescimento de bactérias aerotolerantes, favorecendo a respiração aeróbia epitelial e aumentando a oxigenação da superfície da mucosa (Albenberg et al., 2014).

A maioria dos estudos relacionados à microbiota está concentrado nas bactérias. Entretanto, fungos e vírus podem também estar relacionados com a DII, uma vez que vários genes de suscetibilidade à DII em camundongos e humanos estão envolvidos em respostas imunes antifúngicas, como o CARD9, CLEC7A e RELA (Richard et al., 2015). Com relação aos fungos da microbiota, Sokol et al. (2017) relataram que a diversidade global de fungos era maior em pacientes humanos com DII em relação a indivíduos saudáveis, com várias espécies detectadas apenas em amostras de DC ou CoU. Entretanto, não se pode determinar se os vírus e fungos têm papel direto na patogênese da DII ou se meramente reflete a disbiose subjacente.

\section{O Sistema imune na doença inflamatória intestinal}

O epitélio intestinal é composto por uma única camada de células sob uma lâmina basal que contém uma complexa população de células imunes, com rigoroso controle, que determina a ocorrência de uma tolerância imunológica à antígenos intestinais residentes (Mabbott et al., 2013).

A principal característica da doença inflamatória intestinal é uma pronunciada infiltração na lâmina própria de células inatas imunes (neutrófilos, macrófagos, células dendríticas e células $\mathrm{T}$ natural killer) e células imunológicas adaptativas dos tipos $\mathrm{B}$ e T (Figura 3). O aumento no número e a ativação dessas células na mucosa intestinal elevam os níveis locais de várias citocinas, como fator de necrose tumoral $\alpha$ (TNF- $\alpha$ ), interleucina-1 $\beta$ (IL-1 $\beta$ ), interferon- $\gamma$ (IFN- $\gamma$ ) e IL-23 por Th17 (Dandrieux, 2016). O aumento dos níveis de citocinas pró-inflamatórias, como IL-1, IL-6, IL-18, TNF, e membros da família IL-12 (IL-12, -23, -27, -35), interferon (IFN) - $\alpha$ e IFN- $\beta$ por células apresentadoras de antígenos (APCs), como células dendríticas (CDs) da lâmina própria e macrófagos foram relatados na DII humana (Park et al., 2017).

O Tecido Linfoide Associado a Mucosa (MALT) desempenha um papel fundamental na imunidade adaptativa intestinal, a exposição constante a antígenos alimentares e microbianos requer interações complexas no MALT do hospedeiro para gerar tolerância imunológica ou respostas imunes ativas. Os linfócitos T são células do sistema imune adaptativo e uma parte importante do MALT, e em conjunto com linfócitos B e CDs existem em números elevados na lâmina própria intestinal abaixo das células da mucosa (Heilmann \& Suchodolski, 2015).

A DC é conhecidamente designada como uma condição inflamatória dominada pelos linfócitos Th1, devido à produção elevada de IL-12 e IFN- $\gamma$, enquanto a CoU é caracterizada como uma condição TH2, baseada na produção de IL-5 e IL-13. Entretanto descobriu- se que as células Th17, produtoras de IL17, estão presentes em pacientes com DC, para os quais os linfócitos da mucosa produzem IL-17 e IFN$\gamma$, redefinindo essa forma de DII como uma condição mista Th1 e Th1/Th17 (Pascual et al., 2014). As células Th17 são oriundos de uma linhagem distinta de linfócitos T $\mathrm{CD}^{+}$, pró-inflamatórios, que são 
induzidos por IL-6/IL-21 e produzem IL-17 e IL-23 (Brand, 2009). Essas citocinas oriundas da ativação de Th17 causam graves danos epiteliais, pois induzem ao recrutamento de neutrófilos e estimulam fibroblastos para secretar mais metaloproteinases por meio do aumento dos níveis de IL-1 $\beta$, IL-6, IL-8 e TNF na DC (Park et al., 2017).

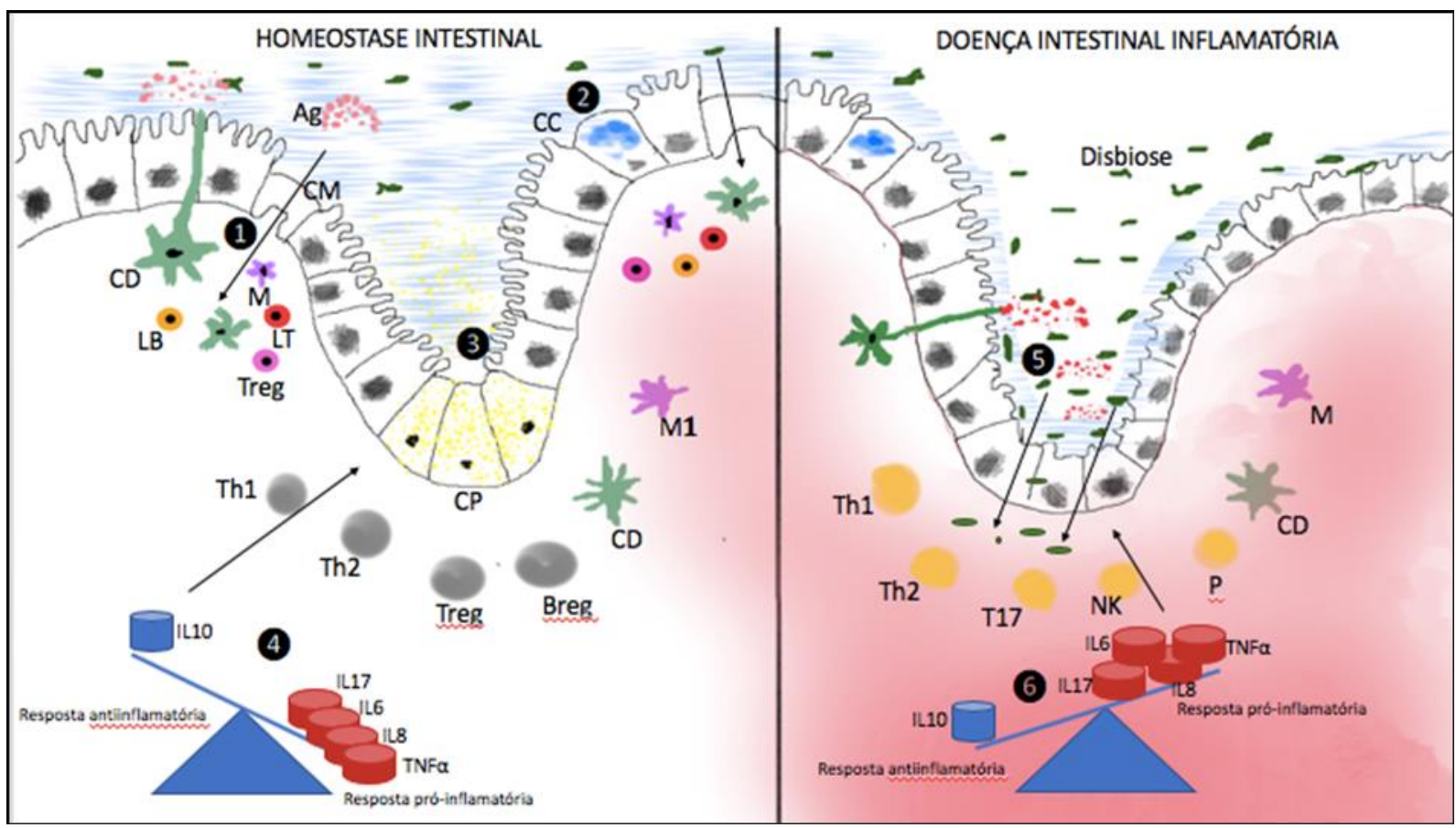

Figura 3. Homeostase imune intestinal e a resposta inflamatória desequilibrada. Fatores como a microbiota, permeabilidade epitelial e resposta imune predominante, são peças chaves para o desenvolvimento da DII. 1) Importantes eventos regem a imunidade inata: Em um ambiente intestinal normal, antígenos luminais são apresentados constantemente para os linfócitos locais, através da endocitose pelas Células $\mathrm{M}$ e pelas projeções citoplasmáticas das CDs, que atingem o lúmen intestinal, capturando peptídeos bacterianos, alimentares, fúngicos e virais (Mabbott et al., 2013). 2) Camada de muco produzido pelas células caliciformes e a secreção de defensinas pelas células de Paneth (3), mantém uma importante proteção da mucosa intestinal ao conteúdo luminal, limitando o crescimento e invasão bacteriano (Birchenough et al., 2015). 4) O estado normal é mediado por um equilíbrio recíproco entre células imunes (Treg e Breg vs. Th1 e Th2) e citocinas que são secretadas para manter as condições no intestino, sobressaindo- se a resposta antiinflamatória. 5) Um desequilíbrio nas células imunológicas leva à destruição das células epiteliais intestinais e à invasão da microbiota comensal. 6) Na DII ocorre à liberação descontrolada de citocinas, perpetuando- se uma resposta inflamatória (Lee et al., 2018). Ag- antígenos do lúmen intestinal; CC - Células caliciformes; CP - Células de Pannet; CM - Células M; CDs - Células dendríticas; LB - Linfócitos B; LT Linfócitos T; M - Macrófago; NK - Linfócitos Natural Killer; P - Plasmócitos.

Em gatos com enteropatia inflamatória, a expressão do gene da IL-23 foi significativamente maior, o que pode suportar a hipótese de que a IL-23 está implicada na imunopatogénese da enteropatia inflamatória felina (Waly et al., 2014). Esta mesma situação foi encontrada na DC.

Métodos imunohistoquímicos foram utilizados para identificar subgrupos de leucócitos dentro da mucosa do duodeno, jejuno e íleo de gatos saudáveis, ao longo do intestino delgado, os plasmócitos $\mathrm{IgA}^{+} \mathrm{e} \mathrm{IgM}^{+}$foram mais proeminentes na lâmina própria adjacente à cripta inferior do que nas vilosidades, enquanto os plasmócitos $\mathrm{IgG}^{+}$estavam presentes em igual número nas regiões cripta e vilosidades. Em geral, os plasmócitos Ig $\mathrm{A}^{+}$predominaram e os plasmócitos $\operatorname{IgM}^{+}$foram mais numerosos do que os plasmócitos $\mathrm{IgG}^{+}$. Em contraste, as células $\mathrm{TCD}^{+} \mathrm{CD}^{+}$e $\mathrm{TCD} 3{ }^{+} \mathrm{CD} 8^{+}$estavam presentes em maior número na lâmina própria da vilosidade do que na lâmina adjacente às criptas (Waly et al., 2001). $\mathrm{O}$ acúmulo de células T nesse nível pode refletir a compartimentalização de células imunes no intestino e pode ser devido aos efeitos das células apresentadoras de antígenos (APCs) (Marsilio et al., 2014).

O compartimento intraepitelial do intestino delgado de gatos saudáveis é dominado por linfócitos T> $85 \%)$ que frequentemente contém grânulos intracitoplasmáticos. Há quantidades elevadas de linfócitos $\mathrm{T} \mathrm{CD} 8 \alpha^{+}$e pequenas porcentagens de linfócitos $\mathrm{T} \mathrm{CD} 4^{+}$, de tal forma que a relação $\mathrm{CD} 4: \mathrm{CD} 8$ é baixa. (Roccabianca et al., 2000). Os linfócitos intraepiteliais também foram caracterizados fenotipicamente, sendo a maioria linfócitos T CD8+ (Waly et al., 2001). 
Outra linhagem de linfócitos importantes na resposta imune intestinal são os linfócitos T reguladores (Treg), que são células T CD4 ${ }^{+}$que expressam o fator de transcrição (FoxP3) e a cadeia $\alpha$ do receptor de IL$2\left(\mathrm{CD} 25^{+}\right)$. São essenciais para o desenvolvimento de tolerância imunológica a antígenos hospedeiros e estranhos, e sua disfunção pode implicar nas patogenias das DII (Park et al., 2017). Na DC, foi observada diminuição na população de células Treg e aumento no número de células Th1 sugerindo que as células Treg são importantes supressores da colite mediada por Th1 (Huibregtse et al., 2007).

Os macrófagos podem ser classificados como macrófagos classicamente ativados ou alternativamente ativados, dependentemente de suas atividades pró-inflamatórias versus imuno regulatórias. São estados funcionais diferentes, mas intercambiáveis, dependendo do microambiente que os macrófagos encontram (Heliö et al., 2003). Na mucosa intestinal saudável, os macrófagos humanos não produzem citocinas pró-inflamatórias, mas retêm atividade fagocítica e bactericida in vitro. Entretanto, em pacientes com DC, foram relatados macrófagos $\mathrm{CD}_{14}{ }^{+}$que exibem marcadores como CD33, CD68 e de células dendríticas (CD205, CD209), que produzem abundantes IL-6, IL-23 e TNF, contribuindo para a produção de IFN- $\gamma$ por células locais (Kamada et al., 2008).

Em um estudo, os macrófagos $\mathrm{L}^{+}$foram significativamente diminuídos na área de criptas mais baixas do cólon de gatos com DII e houve uma tendência a uma diminuição na área da cripta superior do duodeno e do jejuno. Houve marcação com MAC387, que é específico para a calprotectina humana (L1), e que tem sido associada a macrofágos classicamente ativados em tecidos sob condições próinflamatórias. A razão para o menor número de macrófagos L1 + no intestino grosso e delgado de gatos com DII neste estudo não foi clara (Kleinschmidt et al., 2010b). Acredita-se que as CDs tenham um importante papel na patogenia da DII, já que estas são responsáveis por monitorar o microambiente circundante, apresentar antígenos e configurar eventos imunes subsequentes, controlando então a interação entre imunidade inata e adaptativa, induzindo tolerância ou incitando uma resposta próinflamatória do hospedeiro. As CDs da mucosa apresentam propriedades únicas que lhes permitem interagir com as células T e B, o epitélio intestinal e o estroma e, assim, contribuem para a manutenção da homeostase da mucosa ou induzem a inflamação (Rescigno \& Sabatino, 2009). Em gatos com DII foi verificado que a expressão do complexo principal de histocompatibilidade (MHC) classe II por CDs e macrófagos na lâmina própria estava significativamente elevada (Waly et al., 2004). Fato também observado em enterócitos. Estes dados ressaltam uma expressão de MHC classe II de maior intensidade em gatos acometidos por DII.

A participação de mastócitos na DII em humanos e em cães já foi demonstrada (German et al., 2001). Seu papel na DII se deve principalmente pela sua capacidade de influenciar a polarização de uma resposta imune, seja por interação direta com outras células imunes, seja por liberação seletiva do mediador, e sua ação em reações de hipersensibilidade e processos fibróticos (Locher et al., 2001).Os mastócitos são classificados de acordo com o seu conteúdo de proteases: existem os produtores de quimase, triptase ou ambas (Pejler et al., 2007). Ambas podem induzir processos inflamatórios ou antiinflamatórios e reparativos, dependendo do microambiente e de outros mediadores liberados paralelamente, portanto, acredita-se que os mastócitos migram dentro do tecido e alterem suas propriedades histoquímicas dependendo do seu microambiente (Wang et al., 1998).

Em gatos com colite, em comparação com gatos controle, o número de mastócitos produtores de quinase diminuiu, enquanto o número de produtores de triptase foi elevado, o que indica que uma liberação de mediadores para reparo e remodelação do tecido e que os precursores de mastócitos ainda não haviam sido diferenciados para esses subtipos. Estas proteases também podem estimular os fibroblastos diretamente para produzir fibras de colágeno através da hidrólise do receptor ativado por proteases-1 (PAR-1). O aumento de mastócitos produtores de triptase detectado especialmente na região da cripta de gatos com colite pode refletir a participação dessas células no processo de remodelação tecidual, estimulando a fibrose em forma de faixa na interseção entre as vilosidades e as criptas (Kleinschmidt et al., 2010b).

\section{Conclusão}

A Doença inflamatória intestinal ainda é um grande desafio para a medicina veterinária. Estudos atuais já conseguem esclarecer pontos importantes da imunopatogenia, entretanto lacunas ainda permanecem, principalmente na definição de causa ou efeito entre a microbiota intestinal, epitélio intestinal e células 
imunes. Os estudos discutidos até o momento descrevem associações e não provam a causalidade. As evidências sugerem que a disbiose na DII pode, em grande parte, refletir a resposta de uma comunidade microbiana complexa ao estresse ambiental da inflamação intestinal. Assim, conhecer as bases do sistema imunológico associado à mucosa intestinal é fundamental para compreender como acontecem os processos de interação do organismo animal com o meio que o cerca. Apesar do fenótipo de infiltrado linfoplasmocítico da DII felina não se enquadrar em um perfil de citocinas IL-17, pesquisas relacionadas ao papel das células Th17 podem ajudar a esclarecer hiatos importantes da patogenia.

\section{Referências bibliográficas}

Aaron, L., Torsten, M., \& Patricia, W. (2019). Autoimmunity in celiac disease: extra-intestinal manifestations. Autoimmunity Reviews, 18(3), 241-246. DOI: https://doi.org/10.1016/j.autrev.2018.09.010

Albenberg, L., Esipova, T. V, Judge, C. P., Bittinger, K., Chen, J., Laughlin, A., Grunberg, S., Baldassano, R. N., Lewis, J. D., \& Li, H. (2014). Correlation between intraluminal oxygen gradient and radial partitioning of intestinal microbiota. Gastroenterology, 147(5), 1055-1063. DOI: https://doi.org/10.1053/j.gastro.2014.07.020

Birchenough, G. M. H., Johansson, M. E. V, Gustafsson, J. K., Bergström, J. H., \& Hansson, G. C. (2015). New developments in goblet cell mucus secretion and function. Mucosal Immunology, 8(4), 712-719. DOI: https://doi.org/10.1038/mi.2015.32

Brand, S. (2009). Crohn's disease: Th1, Th17 or both? The change of a paradigm: new immunological and genetic insights implicate Th17 cells in the pathogenesis of Crohn's disease. Gut, 58(8), 1152-1167.

Dandrieux, J. R. S. (2016). Inflammatory bowel disease versus chronic enteropathy in dogs: are they one and the same? Journal of Small Animal Practice, 57(11), 589-599. DOI: https://doi.org/10.1111/jsap. 12588

Danese, S., Sans, M., \& Fiocchi, C. (2004). Inflammatory bowel disease: the role of environmental factors. Autoimmunity Reviews, 3(5), 394-400. DOI: https://doi.org/10.1016/j.autrev.2004.03.002

Day, M. J., Bilzer, T., Mansell, J., Wilcock, B., Hall, E. J., Jergens, A., Minami, T., Willard, M., \& Washabau, R. (2008). Histopathological standards for the diagnosis of gastrointestinal inflammation in endoscopic biopsy samples from the dog and cat: a report from the World Small Animal Veterinary Association Gastrointestinal Standardization Group. Journal of Comparative Pathology, 138, S1S43. DOI: https://doi.org/10.1016/j.jcpa.2008.01.001

Duboc, H., Rajca, S., Rainteau, D., Benarous, D., Maubert, M.-A., Quervain, E., Thomas, G., Barbu, V., Humbert, L., \& Despras, G. (2013). Connecting dysbiosis, bile-acid dysmetabolism and gut inflammation in inflammatory bowel diseases. Gut, 62(4), 531-539. DOI: 10.1136/gutjnl-2012-303867

Fragata, F. S., \& Santos, M. M. (2008). Principais Conceitos em Medicina Veterinária Intensiva (Vol. 1). Roca.

Gálvez, J. (2014). Role of Th17 cells in the pathogenesis of human IBD. International Scholarly Research Notices, 2014, 1-14. DOI: https://doi.org/10.1155/2014/928461

Geremia, A., Biancheri, P., Allan, P., Corazza, G. R., \& Di Sabatino, A. (2014). Innate and adaptive immunity in inflammatory bowel disease. Autoimmunity Reviews, 13(1), 3-10. DOI: https://doi.org/10.1016/j.autrev.2013.06.004

German, A. J., Hall, E. J., \& Day, M. J. (2001). Immune cell populations within the duodenal mucosa of dogs with enteropathies. Journal of Veterinary Internal Medicine, 15(1), 14-25. DOI: https://doi.org/10.1111/j.1939-1676.2001.tb02292.x

Grigg, J. B., \& Sonnenberg, G. F. (2017). Host-microbiota interactions shape local and systemic inflammatory diseases. The Journal of Immunology, 198(2), 564-571. DOI: https://doi.org/10.4049/jimmunol.1601621

Heilmann, R. M., \& Suchodolski, J. S. (2015). Is inflammatory bowel disease in dogs and cats associated with a Th1 or Th2 polarization? Veterinary Immunology and Immunopathology, 168(3-4), 131-134. DOI: https://doi.org/10.1016/j.vetimm.2015.10.008

Heliö, T., Halme, L., Lappalainen, M., Fodstad, H., Paavola-Sakki, P., Turunen, U., Färkkilä, M., Krusius, T., \& Kontula, K. (2003). CARD15/NOD2 gene variants are associated with familially 
occurring and complicated forms of Crohn's disease. Gut, 52(4), 558-562. DOI: http://dx.doi.org/10.1136/gut.52.4.558

Hill, R. C., \& Van Winkle, T. J. (1993). Acute necrotizing pancreatitis and acute suppurative pancreatitis in the cat: a retrospective study of 40 cases (1976-1989). Journal of Veterinary Internal Medicine, 7(1), 25-33. DOI: https://doi.org/10.1111/j.1939-1676.1993.tb03165.x

Huibregtse, I. L., Van Lent, A. U., \& Van Deventer, S. J. H. (2007). Immunopathogenesis of IBD: insufficient suppressor function in the gut? Gut, 56(4), 584-592. DOI: http://dx.doi.org/10.1136/gut.2006.103523

Janeczko, S., Atwater, D., Bogel, E., Greiter-Wilke, A., Gerold, A., Baumgart, M., Bender, H., McDonough, P. L., McDonough, S. P., \& Goldstein, R. E. (2008). The relationship of mucosal bacteria to duodenal histopathology, cytokine mRNA, and clinical disease activity in cats with inflammatory bowel disease. Veterinary Microbiology, 128(1-2), 178-193. DOI: https://doi.org/10.1016/j.vetmic.2007.10.014

Jergens, A. E. (2012). Feline idiopathic inflammatory bowel disease: what we know and what remains to be unraveled. Journal of Feline Medicine and Surgery, 14(7), 445-458. DOI: https://doi.org/10.1177\%2F1098612X12451548

Jergens, A. E., Crandell, J. M., Evans, R., Ackermann, M., Miles, K. G., \& Wang, C. (2010). A clinical index for disease activity in cats with chronic enteropathy. Journal of Veterinary Internal Medicine, 24(5), 1027-1033. DOI: https://doi.org/10.1111/j.1939-1676.2010.0549.x

Johnston, K. L., Swift, N. C., Forster-van Hijfte, M., Rutgers, H. C., Lamport, A., Ballàvre, O., \& Batt, R. M. (2001). Comparison of the bacterial flora of the duodenum in healthy cats and cats with signs of gastrointestinal tract disease. Journal of the American Veterinary Medical Association, 218(1), 48-51. DOI: https://doi.org/10.2460/javma.2001.218.48

Kamada, N., Hisamatsu, T., Okamoto, S., Chinen, H., Kobayashi, T., Sato, T., Sakuraba, A., Kitazume, M. T., Sugita, A., \& Koganei, K. (2008). Unique CD14+ intestinal macrophages contribute to the pathogenesis of Crohn disease via IL-23/IFN- $\gamma$ axis. The Journal of Clinical Investigation, 118(6), 2269-2280. DOI: https://doi.org/10.1172/JCI34610

Kathrani, A., House, A., Catchpole, B., Murphy, A., German, A., Werling, D., \& Allenspach, K. (2010). Polymorphisms in the TLR4 and TLR5 gene are significantly associated with inflammatory bowel disease in German shepherd dogs. PloS One, 5(12), e15740. DOI: https://doi.org/10.1371/journal.pone.0015740

Kleinschmidt, S., Harder, J., Nolte, I., Marsilio, S., \& Hewicker-Trautwein, M. (2010a). Chronic inflammatory and non-inflammatory diseases of the gastrointestinal tract in cats: diagnostic advantages of full-thickness intestinal and extraintestinal biopsies. Journal of Feline Medicine and Surgery, 12(2), 97-103. DOI: https://doi.org/10.1016\%2Fj.jfms.2009.07.004

Kleinschmidt, S., Harder, J., Nolte, I., Marsilio, S., \& Hewicker-Trautwein, M. (2010b). Phenotypical characterization, distribution and quantification of different mast cell subtypes in transmural biopsies from the gastrointestinal tract of cats with inflammatory bowel disease. Veterinary Immunology and Immunopathology, 137(3-4), 190-200. DOI: https://doi.org/10.1016/j.vetimm.2010.05.005

Lee, S. H., Kwon, E. J., \& Cho, M.-L. (2018). Immunological pathogenesis of inflammatory bowel disease. Intestinal Research, 16(1), 26-42. DOI: https://dx.doi.org/10.5217\%2Fir.2018.16.1.26

Locher, C., Tipold, A., Welle, M., Busato, A., Zurbriggen, A., \& Griot-Wenk, M. E. (2001). Quantitative assessment of mast cells and expression of IgE protein and mRNA for IgE and interleukin 4 in the gastrointestinal tract of healthy dogs and dogs with inflammatory bowel disease. American Journal of Veterinary Research, 62(2), 211-216. DOI: https://doi.org/10.2460/ajvr.2001.62.211

Mabbott, N. A., Donaldson, D. S., Ohno, H., Williams, I. R., \& Mahajan, A. (2013). Microfold (M) cells: important immunosurveillance posts in the intestinal epithelium. Mucosal Immunology, 6(4), 666-677. DOI: https://doi.org/10.1038/mi.2013.30

Marsilio, S., Kleinschmidt, S., Nolte, I., \& Hewicker-Trautwein, M. (2014). Immunohistochemical and morphometric analysis of intestinal full-thickness biopsy samples from cats with lymphoplasmacytic inflammatory bowel disease. Journal of Comparative Pathology, 150(4), 416-423. DOI: https://doi.org/10.1016/j.jcpa.2014.01.002 
Marsilio, S., \& Steiner, J. (2015). Feline chronic enteropathies. European Journal Comparative and Practice, 25(3), 78-93.

Mosca, A., Leclerc, M., \& Hugot, J. P. (2016). Gut microbiota diversity and human diseases: should we reintroduce key predators in our ecosystem? Frontiers in Microbiology, 7, 455. DOI: https://doi.org/10.3389/fmicb.2016.00455

Ni, J., Wu, G. D., Albenberg, L., \& Tomov, V. T. (2017). Gut microbiota and IBD: causation or correlation? Nature Reviews Gastroenterology \& Hepatology, 14(10), 573. DOI: https://doi.org/10.1038/nrgastro.2017.88

Park, J. H., Peyrin-Biroulet, L., Eisenhut, M., \& Shin, J. Il. (2017). IBD immunopathogenesis: a comprehensive review of inflammatory molecules. Autoimmunity Reviews, 16(4), 416-426. DOI: https://doi.org/10.1016/j.autrev.2017.02.013

Pascual, V., Dieli-Crimi, R., López-Palacios, N., Bodas, A., Medrano, L. M., \& Núñez, C. (2014). Inflammatory bowel disease and celiac disease: overlaps and differences. World Journal of Gastroenterology, 20(17), 4846. DOI: https://dx.doi.org/10.3748\%2Fwjg.v20.i17.4846

Pejler, G., Åbrink, M., Ringvall, M., \& Wernersson, S. (2007). Mast cell proteases. Advances in Immunology, 95, 167-255. DOI: https://doi.org/10.1016/S0065-2776(07)95006-3

Rescigno, M., \& Sabatino, A. (2009). Dendritic cells in intestinal homeostasis and disease. The Journal of Clinical Investigation, 119(9), 2441-2450. DOI: https://doi.org/10.1172/JCI39134

Richard, M. L., Lamas, B., Liguori, G., Hoffmann, T. W., \& Sokol, H. (2015). Gut fungal microbiota: the Yin and Yang of inflammatory bowel disease. Inflammatory Bowel Diseases, 21(3), 656-665. DOI: https://doi.org/10.1097/MIB.0000000000000261

Roccabianca, P., Woo, J. C., \& Moore, P. F. (2000). Characterization of the diffuse mucosal associated lymphoid tissue of feline small intestine. Veterinary Immunology and Immunopathology, 75(1-2), 27-42. DOI: https://doi.org/10.1016/S0165-2427(00)00181-1

Sokol, H., Leducq, V., Aschard, H., Pham, H.-P., Jegou, S., Landman, C., Cohen, D., Liguori, G., Bourrier, A., \& Nion-Larmurier, I. (2017). Fungal microbiota dysbiosis in IBD. Gut, 66(6), 10391048. DOI: http://dx.doi.org/10.1136/gutjnl-2015-310746

Souza, H. S., \& Fiocchi, C. (2016). Immunopathogenesis of IBD: Current State of the Art. Nature reviews Gastroenterology \& Hepatology, 13, 13-27. Nature Reviews Gastroenterology \& Hepatology, 13, 13-27. DOI: https://doi.org/10.1038/nrgastro.2015.186

Suchodolski, J. S. (2016). Diagnosis and interpretation of intestinal dysbiosis in dogs and cats. The Veterinary Journal, 215, 30-37. DOI: https://doi.org/10.1016/j.tvj1.2016.04.011

Waly, N., Gruffydd-Jones, T. J., Stokes, C. R., \& Day, M. J. (2001). The distribution of leucocyte subsets in the small intestine of healthy cats. Journal of Comparative Pathology, 124(2-3), 172-182. DOI: https://doi.org/10.1053/jcpa.2000.0450

Waly, N E, Peters, I. R., Day, M. J., Stokes, C. R., Bailey, M., \& Gruffydd-Jones, T. J. (2014). Measurement of IL-12 (p40, p35), IL-23p19, and IFN- $\gamma$ mRNA in Duodenal Biopsies of Cats with Inflammatory Enteropathy. Journal of Veterinary Internal Medicine, 28(1), 42-47. DOI: https://doi.org/10.1111/jvim.12221

Waly, Nashwa E, Stokes, C. R., Gruffydd-Jones, T. J., \& Day, M. J. (2004). Immune cell populations in the duodenal mucosa of cats with inflammatory bowel disease. Journal of Veterinary Internal Medicine, 18(6), 816-825. DOI: https://doi.org/10.1111/j.1939-1676.2004.tb02627.x

Wang, H.-W., Tedla, N., Lloyd, A. R., Wakefield, D., \& McNeil, P. H. (1998). Mast cell activation and migration to lymph nodes during induction of an immune response in mice. The Journal of Clinical Investigation, 102(8), 1617-1626. DOI: https://doi.org/10.1172/JCI3704

Recebido: 30 de março, 2020. Aprovado: 29 de abril, 2020. Disponível online: 14 julho, 2020.
Licenciamento: Este artigo é publicado na modalidade Acesso Aberto sob a licença Creative Commons Atribuição 4.0 (CC-BY 4.0), a qual permite uso irrestrito, distribuição, reprodução em qualquer meio, desde que o autor e a fonte sejam devidamente creditados. 